\title{
Symptom relief and quality of life after stenting for malignant bile duct obstruction
}

\author{
A B Ballinger, M McHugh, S M Catnach, E M Alstead, M L Clark
}

\begin{abstract}
Palliative treatment is appropriate for most patients with cancer of the head of pancreas. Insertion of a biliary stent relieves jaundice and pruritus but it is not known if stenting affects other symptoms or changes the quality of life. Nineteen patients have completed a standard questionnaire to assess symptom relief and quality of life after stent insertion. After stenting there was complete relief of jaundice and pruritus. Furthermore, there was also considerable improvement in anorexia and indigestion. All patients had anorexia before stent insertion, this was moderate/ severe in $13(68 \cdot 4 \%)$. Anorexia was significantly better $(\mathbf{p}<0.01)$ a week after stenting and this benefit was maintained at 12 weeks $(p<0.01)$. Sixteen $(84 \cdot 2 \%)$ patients complained of indigestion before stenting, moderate/ severe in $11(57.9 \%)$. This was significantly better $(p<0.01)$ a week after stenting with complete relief in six at eight weeks $(p<0.01)$. Fifteen (78.9\%) felt that their mood was good/ very good before stent insertion and this was unchanged even at the 12 week assessment. A similar result was obtained for physical health and level of activity. In conclusion stent insertion not only relieves jaundice and pruritus in these patients but also improves other symptoms and quality of life. The considerable improvement in appetite after stenting was of particular benefit.
\end{abstract}

(Gut 1994; 35: 467-470)

Cancer of the pancreas is now the fourth commonest cause of cancer death in the United Kingdom and USA. For most patients the tumour is unresectable ${ }^{1}$ and radiotherapy and chemotherapy, either alone or together with surgery, have given disappointing results. ${ }^{2-4}$ Overall the median survival has not changed in recent years and remains at four to five months. For most patients with this condition, treatment is therefore aimed at palliation of symptoms and maintaining quality of life in the few months between diagnosis and death. The predominant symptoms are jaundice, pruritus, anorexia, pain, and indigestion. Placement of a biliary stent, at endoscopic retrograde cholangiopancreatography (ERCP) effectively relieves jaundice and pruritus. ${ }^{5}$ The aim of this study was to assess if stenting affects symptoms other than jaundice and pruritus and changes the subsequent quality of life.

\section{Patients and methods}

This study was approved by the ethics committee of Waltham Forest Health Authority and
City and Hackney Health Authority. Patients were recruited from St Bartholomew's Hospital and Whipps Cross Hospital, all patients gave informed consent before entering the study. Between 1 January and 1 October 1992 all patients with cancer of the head of pancreas, referred for endoscopic stent insertion, were recruited. The diagnosis was initially made on a typical history and the presence of a mass in the head of the pancreas and dilated bile ducts on ultrasound examination or computed tomography. This has been shown to be sensitive and specific for the diagnosis of pancreatic cancer and cytology/histology is not necessary to make a definitive diagnosis. ${ }^{6}$ In most of our patients, however, a tissue diagnosis was made at the first ERCP or at a later date. Patients were followed up until the time of death or until the time of writing this report. A three part questionnaire was used to assess symptoms and quality of life. Each part of the questionnaire has been validated in previous studies: (1) the Rotterdam Symptom Checklist $^{7}$ with two further questions to assess jaundice and pruritus. Each of these symptoms is rated on a four point scale from 'not at all' (score 0 ) to 'very much' (score 3); (2) the Hospital Anxiety and Depression Scale (HAD), which is a brief but useful assessment of anxiety and depression. Fourteen items are divided into two subscales for anxiety and depression, each item rated on a 4 point scale from 'very often' (score 3 ) to 'not at all' (score 0). The maximum score that can be obtained on each scale is 21 . A score of 11 or more on either scale suggests definite anxiety or depression and a score of 8-10 suggests a possible diagnosis of depression or anxiety ; (3) a further section to assess site and severity of pain,? mood (score $1-4,1=$ bad, $4=$ very good), the patients' perception of their physical health (score $1-5,1=$ very bad, $5=$ very good) and level of activity. Patients were also asked if they had any other symptoms not previously noted and what treatment they were taking. The type and quantity of food that they had eaten on the day before the assessment was also recorded.

The questionnaire was completed by the patient before the first ERCP and then at 1, 4, 8, and 12 weeks after stent insertion. To ensure complete follow up throughout this study all patients were visited at home by a research nurse (MMcH), the questionnaire given to the patient, and completed by the patient during that visit. At the beginning of the study the patients were told that we wanted to assess their symptoms over a period of time. They were not told that the purpose of the study was specifically to assess the effect of stenting on symptom relief as this may have biased their answers. Symptoms were assessed over a 12 week period after stent insertion. It was felt that after this time many patients would 
TABLE I Nineteen consecutive patients stented for malignant bile duct obstruction

\begin{tabular}{|c|c|}
\hline Age & 69 (range $45-79)$ \\
\hline Sex & $11 \mathrm{M} / 8 \mathrm{~F}$ \\
\hline $\begin{array}{l}\text { Serum bilirubin before } \\
\text { stenting (normal range 2-17 } \\
\mu \mathrm{mol} / \mathrm{l} \text { ) }\end{array}$ & $186(124-286)$ \\
\hline Mean survival (weeks) & $\begin{array}{l}31 \text { (includes } 3 \text { patients alive at } \\
\text { the time of writing } 36,48 \text {, and } \\
52 \text { weeks after diagnosis) }\end{array}$ \\
\hline $\begin{array}{l}\text { Symptomatic late duodenal } \\
\text { obstruction }\end{array}$ & $1(5 \%)$ \\
\hline \multicolumn{2}{|l|}{ No of stents ( $11.5 \mathrm{~F}$ polyethylene) } \\
\hline & $\begin{array}{l}13 \text { patients of whom one is still } \\
\text { alive }\end{array}$ \\
\hline 2 & $\begin{array}{l}6 \text { patients of whom one is still } \\
\text { alive }\end{array}$ \\
\hline
\end{tabular}

At the time of writing 16 patients have died and three remain alive.

enter the terminal stages of their disease and the symptom assessment would only reflect this. After completion of the study period a record was kept of any complications developing including the time of death.

STATISTICAL ANALYSIS

Unless otherwise stated the symptom scores are presented as the median and the interquartile range. A comparison was made between the scores before and after stent insertion using the Wilcoxon signed rank test.

\section{Results}

Twenty three patients with jaundice secondary to cancer of the head of pancreas were referred for ERCP and stent insertion. Twenty one (91\%) patients were successfully stented either endoscopically or transhepatically during a combined procedure. In two patients a stent could not be placed and they were referred for a surgical bypass procedure. Of the original 21 patients one patient died three days after stent insertion and one patient refused further participation in the study after completing the first questionnaire. Table I summarises patient characteristics and survival times. The results of the questionnaires are presented for the 19 patients who were stented and completed at least one follow up questionnaire. At the four week assessment the results are presented for the 18 patients who remained alive and similarly at the 12 week assessment the results are presented for the remaining 16 patients.

\section{JAUNDICE AND PRURITUS}

As expected, stenting was a very effective treatment for both jaundice and pruritus. All patients were jaundiced before stent insertion and there was a significant improvement one week after

TABLE II Symptom scores before stenting and at the one week and eight week assessment

\begin{tabular}{lllll}
\hline & $\begin{array}{l}\text { Before } \\
\text { stenting }\end{array}$ & $\begin{array}{l}\text { lWeek after } \\
\text { stenting }\end{array}$ & $\begin{array}{l}4 \text { Weeks } \\
\text { after stenting; }\end{array}$ & $\begin{array}{l}8 \text { Weeks } \\
\text { after stenting }\end{array}$ \\
\hline Jaundice & $3(2-3)$ & $1(0-2)$ & $0(0-1)$ & $0(0-0)$ \\
Pruritus & $1(0-3)$ & $0(0-0)$ & $0(0-0)$ & $0(0-0)$ \\
\hline
\end{tabular}

Results are expressed as the median (range) for the 19 study patients. One week after stent insertion the symptom scores for both jaundice and pruritus were significantly $(p<0.01)$ improved compared with before stenting. stenting with complete relief by eight weeks in all except one patient who remained mildly jaundiced. Eleven $(57.9 \%)$ patients complained of pruritus before stent insertion. There was significant improvement one week after stenting with complete relief at the eight week assessment. These benefits were maintained at the 12 week assessment (Table II).

\section{ANOREXIA AND INDIGESTION}

Anorexia was a.prominent symptom in all patients before stent insertion. This was severe (grade 3) in eight (42.1\%) and moderate (grade 2) in five $(26.3 \%)$ patients. Appetite was significantly improved one week after stent insertion and at the 12 week assessment anorexia was completely relieved (grade 0 ) in seven of 10 surviving patients who initially had grade $2 / 3$ anorexia. In one patient anorexia was worse after stenting, from a score of 2 before stenting to 3 at the 12 week assessment (Fig 1). From the patients' records they ate more and left less food after stenting. As the food was not weighed by the patients, however, we cannot accurately translate this into number of calories consumed. Eight patients were weighed at each assessment and there was no significant change (mean $(\mathrm{SEM}))$ at the 12 week assessment $(56 \cdot 5(12) \mathrm{kg})$ compared with before stenting $(58 \cdot 1(11))$.

Sixteen $(84 \cdot 2 \%)$ patients complained of indigestion (heartburn, bloating, and wind) before stent insertion, this was moderate/severe in $11(57 \cdot 9 \%)$. One week after stenting this symptom had significantly improved in all except two patients and this benefit was maintained at both the 8 and 12 week assessment (Fig 2).

\section{OTHER SYMPTOMS}

Nine $(47 \cdot 3 \%)$ patients were pain free before stenting, eight had mild/moderate pain, and three had severe pain. There was no significant change in pain scores at any assessment and at the 12 week assessment eight of $16(50 \%)$ surviving patients were pain free. Five of $19(26 \cdot 3 \%)$ patients complained of mild nausea (grade 1) before stenting. In four this was completely relieved after stenting. In two patients, however, nausea developed after stenting at the eight week

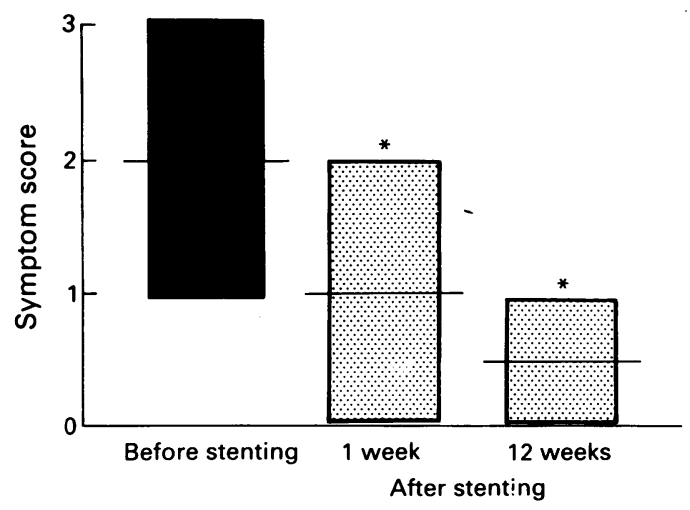

Figure 1: Anorexia before stent insertion and at one and 12 weeks after stenting. Results are expressed as the median and interquartile range. ${ }^{\star} p<0.01$ compared with the score before stenting. There was no significant change between the one week and 12 week assessment. 
assessment. All patients complained of feeling tired before stent insertion (median 2, range 1-3) and there was no significant change after stenting at any assessment. Other than constipation in two patients there were no additional symptoms in this group of patients.

\section{MOOD, ANXIETY, AND DEPRESSION}

Surprisingly most patients felt that their physical health was very good/good before stent insertion (4 (3-4)) and there was no significant change at any assessment. Despite progression of the underlying malignancy, even at 12 weeks eight $(50 \%)$ of the surviving patients reported that their health was very good/good. Similarly there was no change in mood over the 12 week period. Fifteen $(78.9 \%)$ reported that their mood was good/very good before stenting and 13 of the surviving $16(81.25 \%)$ reported that their mood was good/very good at the 12 week assessment.

From the HAD scale two patients had a score of $>8$ ( 8 and 9 ) on the depression scale and this score was reduced to less than eight ( 7 and 4$)$ in both patients after stent insertion. Overall, however, stenting had no significant effect on the scores for depression at any assessment. The scores for anxiety were significantly $(p<0.03)$ reduced after stenting until the eight week assessment (before stent $4(2-6)$, eight weeks after stent $1 \cdot 5(0-5)$ ), but this benefit was not maintained at 12 weeks when the scores were unchanged from before stent insertion.

\section{STANDARD ENDOSCOPIC STENTING $V$ COMBINED} PROCEDURE

Fifteen of 19 patients were stented with the endoscope (group 1). In four patients endoscopic stenting was unsuccessful and they were stented transhepatically during a combined procedure (group 2). The combined procedure is much more invasive than standard endoscopic stenting and symptom relief and quality of life may differ initially after the two procedures. In particular there may be more pain and associated depression and anxiety after the combined procedure. The change in scores before stenting and one week after stenting have been compared (Wilcoxon rank sum test) and no significant difference found between the two groups. This

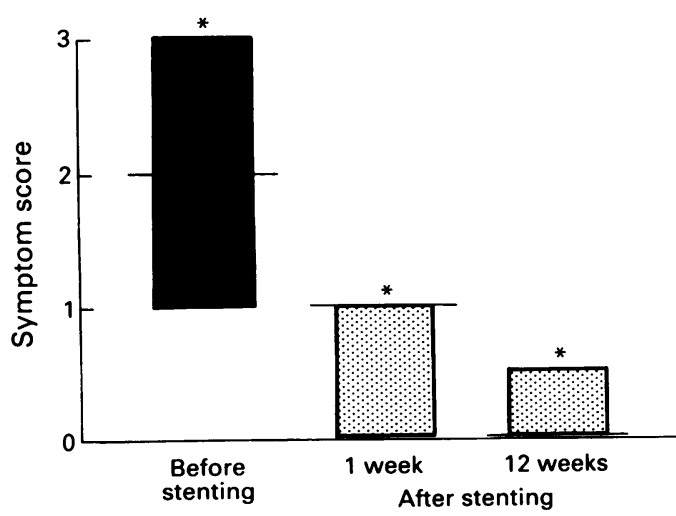

Figure 2: Indigestion before stent insertion and at one and 12 weeks after stenting. Results are expressed as the median and weeks after stenting. Results are expressed as the median and
interquartile range. ${ }^{\star} p<0.01$ compared with the score before stenting. There was no significant change between the one week and 12 week assessment. may be because of the small number of patients in group 2, however, only one patient in this group reported more severe pain after the combined procedure (mild before stent, moderate after stent). Two reported less pain (severe to mild) and one patient remained pain free.

\section{Discussion}

In this study stent insertion completely relieved jaundice and pruritus. Of the 16 patients who have been followed up until the time of death most required one stent and only one patient developed symptomatic duodenal obstruction because of tumour expansion (Table I). These results are in agreement with previous studies, which have shown that most patients die with their original stent in situ and there is a low incidence of late duodenal obstruction. ${ }^{9}$

Surprisingly most patients felt that their physical health and mood was good before stent insertion and despite progression of the underlying malignancy $50 \%$ reported good health up to the 12 week assessment. It is often stated that depression is a common symptom of pancreatic cancer, but in this study only two patients $(11 \%)$ scored more than 8 on the HAD scale before stent insertion and in both of these patients they scored less than 8 at each assessment after stent insertion.

The most interesting finding from this study, however, was the considerable improvement in appetite and indigestion after stenting. Although it is not clear why stenting and relief of jaundice should improve appetite, we can propose several theories. Tumour necrosis factor (TNF) and the interleukins 1 and 6 (IL-1, IL-6) are thought to mediate the anorexia and weight loss associated with malignancy and chronic infection. ${ }^{10-12}$ The exact mechanism of action is not known. Rats with ligated bile ducts develop anorexia and weight loss postoperatively and this is associated with a rise in serum concentrations of these cytokines. Separate experiments have shown high concentrations of circulating endotoxins in animals with ligated bile ducts ${ }^{14}$ and endotoxaemia may in turn stimulate macrophages to produce TNF and the interleukins. It is possible that a similar situation may occur in humans with obstructed bile ducts and cytokine concentrations return to normal after stenting, with relief of anorexia.

Cholecystokinin is a peptide hormone present in endocrine cells of the duodenum and jejunum. It is released in to the portal system in response to the presence of food in the gut. ${ }^{15}$ Pancreatic trypsin exerts a negative feedback on cholecystokinin release ${ }^{16}$ and certainly in animals there is evidence that bile in the duodenum also inhibits release of cholecystokinin. ${ }^{17}$ Cholecystokinin is perhaps best known as the main mediator of postprandial gall bladder contraction but it is also thought to be an important satiety hormone in both animals ${ }^{18}$ and humans. ${ }^{1920}$ In patients with biliary/pancreatic obstruction secondary to pancreatic cancer there may be loss of the negative feedback pathway and consequently a rise in plasma concentrations of cholecystokinin and therefore early satiety and reduced food intake. 
The last eight patients recruited have been weighed at each visit and their weight has not changed significantly from before stenting at the 12 week assessment. All of these patients had lost weight at presentation but simply by stent insertion and relief of jaundice further weight loss was prevented.

There is no untreated control group in this study as we felt it was unethical to withhold treatment from some patients in view of the known benefits of stent insertion for relief of jaundice and pruritus. The two patients who eventually had a surgical bypass, however, were assessed after the attempt at stenting and their symptom scores had not changed.

In conclusion stent insertion not only relieves jaundice and pruritus but significantly improves the other important symptoms of cancer of the pancreas and enhances patients assessment of their quality of life. The mechanism of anorexia in these patients is not understood and further detailed studies are in progress.

These data have been published in abstract form. Gut 1992; 33: A233.

We wish to acknowledge the financial support of the Hackney Nursing Association and the Joint Research Board and Cancer Research Committee of St Bartholomew's Hospital.

1 Connelly MM, Dawson PJ, Michelassi F, Moossa AR, Lowenstein F. Survival in 1001 patients with carcinoma of the pancreas. Ann Surg 1987; 206: 366-73.

2 Oaki H, Hog K, Kato H, Kinoshita T, Egawa S, Kishi K. Multi disciplinary treatment for resectable pancreatic cancer. Int $\mathcal{F}$ Pancreatol 1988; 3: 249-60.

3 Crown J, Casper ES, Botet J, Murray P, Kelsen DP. Lack of efficacy of high-dose leucovorin and fluorouracil in patients with advanced pancreatic adenocarcinoma. $\mathcal{F}$ Clin Oncol 1991; 9: 1682-6.
4 Arbuck SG. Overview of chemotherapy for pancreatic cancer. Int F Pancreatol 1990; 7: 209-22.

Huddart RA, Hubbard CS, Dickinson RJ. Biliary stenting for malignant jaundice. Clin Radiol 1991; 43: 103-6.

6 American Society for Gastrointestinal Endoscopy Washington: ASGE policy and procedure manual. ASGE Wublication No 1003, 1990.

7 de Haes KJM, van Knippenberg FCE, Neijt JP. Measuring psychological and physical distress in cancer patients: structure and application of the Rotterdam Symptom Checklist. Br F Cancer 1990; 62: 1034-8.

8 Zigmund AS, Snaith RP. The hospital anxiety and depression scale. Acta Psychiatr Scand 1983; 67: 361-70.

9 Andersen JR, Sorensen SM, Kruse A, Rokkjaer M, Matzen P. Randomised trial of endoscopic endoprosthesis versus operative bypass in malignant obstructive jaundice. Gut 1989; 30: 1132-5.

10 Balkwill F, Osborne R, Burke F, Naylor S, Talbot D, Durbin $\mathrm{H}$, et al. Evidence for tumour necrosis factor/cachectin $\mathrm{H}$, et al. Evidence for tumour necrosis fact

11 production in cancer. Lancet 1987 ; ii: $1229-32$. CA. Interleukin-1 - induced anorexia in the rat. $\mathcal{F}$ Clin Invest 1989; 84: 228-35.

12 Oliff A, Defeo-Jones D, Boyer M, Martinez D, Kiefer D, Vuocolo G, et al. Tumors secreting human THF/cachectin induce cachexia in mice. Cell 1987; 50: 555-63.

13 Bemelmans MH, Gouma DJ, Greve JW, Buurman WA. Cytokines, tumour necrosis factor and interleukin-6 in experimental biliary obstruction in mice. Hepatology 1992; 15: 1132-6.

14 Diamond T, Dolan S, Thompson RL, Rowlands BJ. Development and reversal of endotoxaemia and endotoxin-related death in obstructive jaundice. Surgery 1990; 108: 370-4

15 Liddle RA, Goldfine ID, Rosen MS, Taplitz A, Williams JA. Cholecystokinin bioactivity in human plasma, molecular forms, responses to feeding and relationship to gallbladder contraction. F Clin Invest 1985; 75: 1144-52.

16 Owyang C, May D, Louie DS. Trypsin suppression of pancreatic enzyme secretion, differential effect on cholepancreatic enzyme secretion, differential effect on cholecystokinin release and the

17 Nakamura R, Miyasaka K, Kuyama Y, Kitani K. Luminal bile regulates cholecystokinin release in conscious rats. Dig Dis Sci 1990; 35: 55-60.

18 Canova A, Geary N. Intraperitoneal injections of nanogram CCK-8 doses inhibit feeding in rats. Appetite 1991; 17: 221-7.

19 Ballinger $\mathrm{AB}$, Clark ML. L-phenylalanine releases cholecystokinin and is associated with reduced food intake in humans. Gastroenterology 1992; 102: A542.

20 Hill AJ, Peikin SR, Ryan CA, Blundell JA. Oral administration of proteinase inhibitor II from potatoes reduces energy intake in man. Physiol Behav 1990; 48: 241-6. 